\title{
The Role of Social Media Marketing Activities on Customer Equity Drivers and Customer Loyalty
}

\author{
Vika Ansy Anggraini ${ }^{1}$ and Arga Hananto ${ }^{2 *}$ \\ ${ }^{1,2}$ Universitas Indonesia, Depok, Indonesia
}

\begin{abstract}
During the past few years, adoption of e-commerce in Indonesia has been increasing along with other trends in information, communication and technology sector such as widespread use of smartphones and social media. To promote its services, e-commerce firms have also embraced social media and carry out social media marketing activities. This study is aimed to test the influence of social media marketing activities toward customer loyalty through customer equity drivers (i.e. Value Equity, Brand Equity, dan Relationship Equity.). A survey was conducted using convenience sampling technique to select respondents. A total of 161 usable responses were used in the main data analysis. This study found support for the five dimensions of social media marketing activities suggested from previous study. Furthermore, this study found that social media marketing activities affect value equity, brand equity and relationship equity. This study also found that two customer equity drivers (brand equity and relationship equity) had a positive effect on customer loyalty, while value equity had a positive effect on customer loyalty, but it was not significant. Discussion and managerial implications were also discussed in this study.
\end{abstract}

Keywords: Brand equity, customer equity drivers, customer loyalty, relationship equity, social media marketing activities, value equity.

\section{Introduction}

Firms are increasingly keen on using social media to build presence and connect with their stakeholders (Chatterjee \& Kumar Kar, 2020). This trend has been fueled primarily by the large number of active social media users that have reached 3.80 billion active social media users as of January 2020 (Kemp, 2020). Social media marketing is defined as the use of social media channels and technologies (including applications) to create, communicate, deliver and exchange valuable offerings with organization's stakeholders (Tuten \& Solomon, 2018). Jacobson, Gruzd, \& Hernández-García (2020) summarized the various use of social media to support firms' marketing, such as to promote and sell products, share information, encourage user engagement, build a relationship and long-term relations, etc.

Past studies have linked social media marketing activities with loyalty (e.g., Balakrishnan, Dahnil, Yi, Yadav, \& Rahman, 2018; Ismail, 2017; Yadav \& Rahman, 2018). Ismail (2017) highlighted that the literature on branding has suggested that firms can increase consumer loyalty toward their brands by building consumer-brand relationships, as the relationship can bring in many benefits to the consumers such as special price, special treatment, and improved service, which in turn might increase the consumers' satisfaction toward the brand. Social media can aid marketers to achieve brand loyalty since social media has the potential to build engagement and relationship (e.g., Barger, Peltier, \& Schultz, 2016; Hudson, Huang, Roth, \& Madden, 2015; Lee, Hosanagar, \& Nair, 2018; Liu, Shin, \& Burns, 2019). Yadav \& Rahman (2018) propose that social media marketing's link with brand loyalty is mediated by brand equity drivers (value equity, brand equity and relationship equity) that follow the stimulus-organismresponse (S-O-R) that was reconceptualized by Jacoby (2002).

* Corresponding author. Email address: $\underline{\text { arga.hananto@ui.ac.id }}$ 
E-commerce firms also apply social media marketing to communicate with their target markets. For instance, Indonesia's top e-commerce firms such as Tokopedia, Shopee, Bukalapak, Lazada, and Blibli (Kemp \& Moey, 2019) all have a presence in social media. Through social media, these e-commerce firms try to reach and engage their target markets. Just like any firms in the market, e-commerce firms also face the need to develop the long-term value of the firm by building customer equity, which according to (Lemon, Rust, \& Zeithaml, 2001) can be built through its three drivers, namely value equity, brand equity, and relationships equity. Ou and Verhoef (2017) summarized customers' equity drivers as "customers' assessment of value received, brand image received, and relationships established." The loyalty literature suggested that these three customer equity drivers have a significant influence on loyalty intentions (Ou \& Verhoef, 2017; Yadav \& Rahman, 2018). In this study, the authors are interested in investigating whether social media marketing activities engaged by Indonesia's the top five e-commerce firms affect the value equity drivers and ultimately, on the loyalty intentions of e-commerce customers. This study replicates study by Yadav \& Rahman (2018). Yadav and Rahman (2018) 's study was conducted in India, on students who were customers of e-commerce sites that were operating in India (such as Amazon or Flipkart). In this study, the authors applied Yadav and Rahman's model within the Indonesian context to gain insight, whether the model they propose also holds in the Indonesian context. Even though this study replicates Yadav and Rahman's model, this study still provides some contributions to the body of knowledge in terms of validating the model in another geographic context. This validation effort would arguably provide more insights as to the universality of the models under different market and culture. The structure of this paper is as follows: theoretical framework will be presented in the next section, followed by hypothesis development, research methodology, result and discussion, and conclusion.

\section{Literature Review and Hypothesis Development 2.1. Social media marketing and its dimensions}

Social media consists of a group of Web 2.0 Internet-based applications (such a social networking site, blog, wikis, social worlds, etc.) that allow its users to create user-generated contents, and it can be integrated with a variety of sites in the form of user reviews, ratings, recommendations, forums and communities (Hajli, 2015; Kaplan \& Haenlein, 2010). It not uncommon for firms, including e-commerce firms, to set up a presence in various social media platforms to help introduce their products and services and encourage their customers to share their comments (Hajli, 2015). These activities may be regarded as social media marketing activities.

Chang, Yu, \& $\mathrm{Lu}$ (2015) defined social media marketing as the use of social networks to share content, diffuse innovation, build a relationship and build fans cohesion, while some other researchers like Tuten \& Solomon (2018) define social media marketing as "the utilization of social media technologies, channels, and software to create, communicate, deliver and exchange offerings that have value for an organization's stakeholders." These two definitions were only two examples of varying social media marketing definitions in the literature. Nevertheless, Yadav and Rahman (2017) suggest that despite having different definitions, the definitions proposed in the literature share similar components, i.e., the use of social media platforms as well as efforts to encourage users to share social media marketing content through social media marketing activities (e.g. interaction, personalization, word of mouth). According to Tuten \& Solomon (2018), all social media share similar nature such as being technologically enabled, networked around relationships and operate based on the principles of shared participation. This nature coincides with relationship marketing paradigm, which, according to Gronroos (1994) is characterized by long term focus, quality interaction with customers, interactivity and real-time customer feedback 
system. Thus, social media can be regarded as a part of marketing and particularly relationship marketing (Yadav \& Rahman, 2017).

As social media becomes widely adopted by people globally, marketers have turned to social media to reach their customers and drive customer engagement (Hudson et al., 2015). For example, a company can set up a Facebook page and invite customers to share their comments about the company's products, which could help the company to market its products (Hajli, 2015). Research has substantiated the benefits of having a social media marketing strategy in place. For instance, a study by Hudson et al. (2015) suggests that social media has a positive relationship with brand relationship quality. Social media marketing was also found to have a positive impact on businesses such as in better customer relationship, increased sales, enquiries and more positive feedbacks (Chatterjee \& Kumar Kar, 2020). Besides, social media marketing was also found to have a significant effect on brand loyalty (Ismail, 2017).

(Yadav \& Rahman, 2018) suggest five dimensions that comprise the perceived social media marketing activities, namely perceived interactivity, perceived personalization, perceived informativeness, perceived trendiness, and perceived word of mouth. Each of the five dimensions is explained in the following paragraphs.

2.1.1. Perceived Interactivity

One of the most important features of social media is that it facilitates interaction (Kim \& Ko, 2012). Yadav \& Rahman (2018) defined perceived interactivity as "customers' perception about the extent to which e-commerce's social media facilitates customers to share content and views with the company and other customers. Godey et al. (2016) indicate that social interaction serves as an important factor that motivates users to generate content since users tend to contribute to brand-related social media platforms to meet, interact and converse with other people about specific product/brands. According to Kim \& Ko (2012), interactions between customers facilitated by social media sites such as Facebook and Twitter can build awareness. In some cases, Kim and Ko (2012) add that it might lead to affection toward brands and stimulates the customers' desire for the brand's value proposition.

2.1.2. Perceived informativeness.

This dimension refers to customers' perception about the accuracy, usefulness and comprehensiveness of the information offered by e-commerce's social media (Yadav \& Rahman, 2018). Previous research by Lee \& Hong (2016) included informativeness as one of the factors that affect user response toward social media advertising. They suggest that informative advertising on social media can attract attention and drive positive consequences toward the advertised brand, such as positive image and desire to share the message with other users. Yadav and Rahman (2018) explained that informativeness might be important for online customers since they tend to buy a product based on accurate and sufficient information from many online sources such as social media or e-commerce sites. These studies suggest that effective social media marketing activities (including, but not limited to) advertising require message informativeness to yield positive consequences for the marketer and the brands they promote.

2.1.3 Perceived word of mouth (perceived WOM)

Electronic word of mouth (EWOM) allows customers to share their opinion and experiences with other customers. Customers regard information from EWOM as highly credible and trustworthy (Cheung, Pires, \& Rosenberger, 2019). In this study, perceived word of mouth refers to this type of EWOM shared by customers with other customers. Yadav and Rahman (2018) defined perceived WOM as the degree to which customers provide recommendation and share their experience with an e-commerce brand on social media. Cheung \& Thadani (2012) suggest that prior to purchasing a new product, over 90 per cent of respondents indicated that they look at online reviews, blogs and other forms of user-generated contents. Moreover, studies indicate that online reviews tend to significantly affect consumers' purchase decision.

2.1.4. Personalization 
Before the advent of social media, marketers have employed the personalization strategy for advertising purposes. Through personalized advertising, marketers can engage customers on a personal level to develop a more effective relationship and meet customer needs (Shanahan, Tran, \& Taylor, 2019). The increased social media proliferation along with e-commerce and smartphones allow firms to gather and analyze a vast amount of data that can be used to customize the firm's interaction with customers, highlight specific, relevant products according to what the customer searched in the e-commerce web site/mobile application, etc. (Shanahan et al., 2019)

Perceived personalization refers to the degree to which an e-commerce's social media provides tailored services to meet customer preferences (Yadav \& Rahman, 2018). Based on previous studies, Maslowska, Smit, \& van den Putte (2016) suggest that the three most popular personalization strategy consists of raising expectation (e.g. by including statements like "this offer is just for you", etc.), identification (e.g. identify customers by name), and contextualization (i.e. framing a message with a context that is meaningful to the customer using contextual variable such as social identifties; an example of this technique for instance by showing pictures depicting people from the same age, gender and ethnicity as the receiving customer). The three techniques can affect customers in several ways. Maslowska et al. (2016) suggest that raising expectation can evoke self-referencing, and create positive expectation, while identification can evoke feelings of closeness and familiarity, and contextualization is suggested to attract attention and increase the motivation to process the message.

2.1.5. Perceived trendiness

With the rise of social media, customers started to demand the latest and trendiest information related to a brand (Liu et al., 2019). (Yadav \& Rahman, 2018) defined perceived trendiness as the extent to which customers perceive that e-commerce's social media offers trendy content. (Kim \& Ko, 2012) indicated that trendiness is reflected by two key terms/phrases: "newest information" and "trendy". Based past studies, Cheung, Pires, Rosenberger, Leung, \& Ting (2020) contend that the trendier the information provided in a brand's social media pages, the more effective the brand's posts in those pages in increasing their customers' motivation to learn more about the brand, hence supporting the rationale of keeping social media brand pages up to date.

\subsection{Customer equity drivers (CED)}

Customer equity drivers (CED) which consist of value equity, brand equity and relationship equity were proposed by (Zeithaml, Lemon, \& Rust, 2001) as drivers of loyalty intentions. Based on the work of (Lemon et al., 2001; Rust, Lemon, \& Zeithaml, 2004), Ou, Verhoef, \& Wiesel (2017) defined the three customer equity drivers as follows. Value equity refers to customers' objective evaluation of the utility provided by a product based on what is given up for what is received; it reflects the result of the comparison between customer expectation and marketer performance. Meanwhile, brand equity refers to customers' intangible and subjective evaluation of the brand image, which consists of brand strength and brand innovativeness (Ou et al., 2017). Lastly, the third CED, relationship equity refers to the customers' overall evaluation of their interaction quality with a company. This definition is somewhat more specific and elaborates the definition provided in Lemon et al. (2001) as "the tendency of the customer to stick

with the brand, above and beyond the customer's objective and subjective assessments of the brand. Relationship equity is built upon customers relationships with firm personnel (e.g. sales and service personnel), loyalty programs, customer communities, and knowledge-building programs (Lemon et al., 2001; Ou, de Vries, Wiesel, \& Verhoef, 2014). These programs are intended to create and sustain firm bonds with customer while reducing cost in the process (Lemon et al., 2001). 


\subsection{Customer loyalty}

Loyalty is regarded as one of the prime focus of marketing (Yadav \& Rahman, 2018). Oliver (1999) defined loyalty as "a deeply held commitment to rebuy or repatronize a preferred product/service consistently in the future, thereby causing repetitive same-brand or same brand-set purchasing, despite situational influences and marketing efforts having the potential to cause switching behavior." Past research has suggested that loyalty presents many benefits for marketers. For instance, (Tran \& Strutton, 2020) summarized several benefits that come from achieving customer loyalty, such as additional purchases, less brand switching, lower marketing costs (due to less need to acquire new customers), opportunity to boost revenue by asking loyal customers to buy more, and opportunity to get word of mouth from loyal customers, since they would be more willing to engage in spreading word of mouth (in person or through e-channels).

\section{Conceptual Framework and Hypothesis Development}

This study follows the research model proposed in Yadav \& Rahman (2018). Yadav and Rahman (2018) studied how social media marketing activities affect customer loyalty toward e-commerce sites through three customer equity drivers. Figure 1 shows the research model adopted in this study.

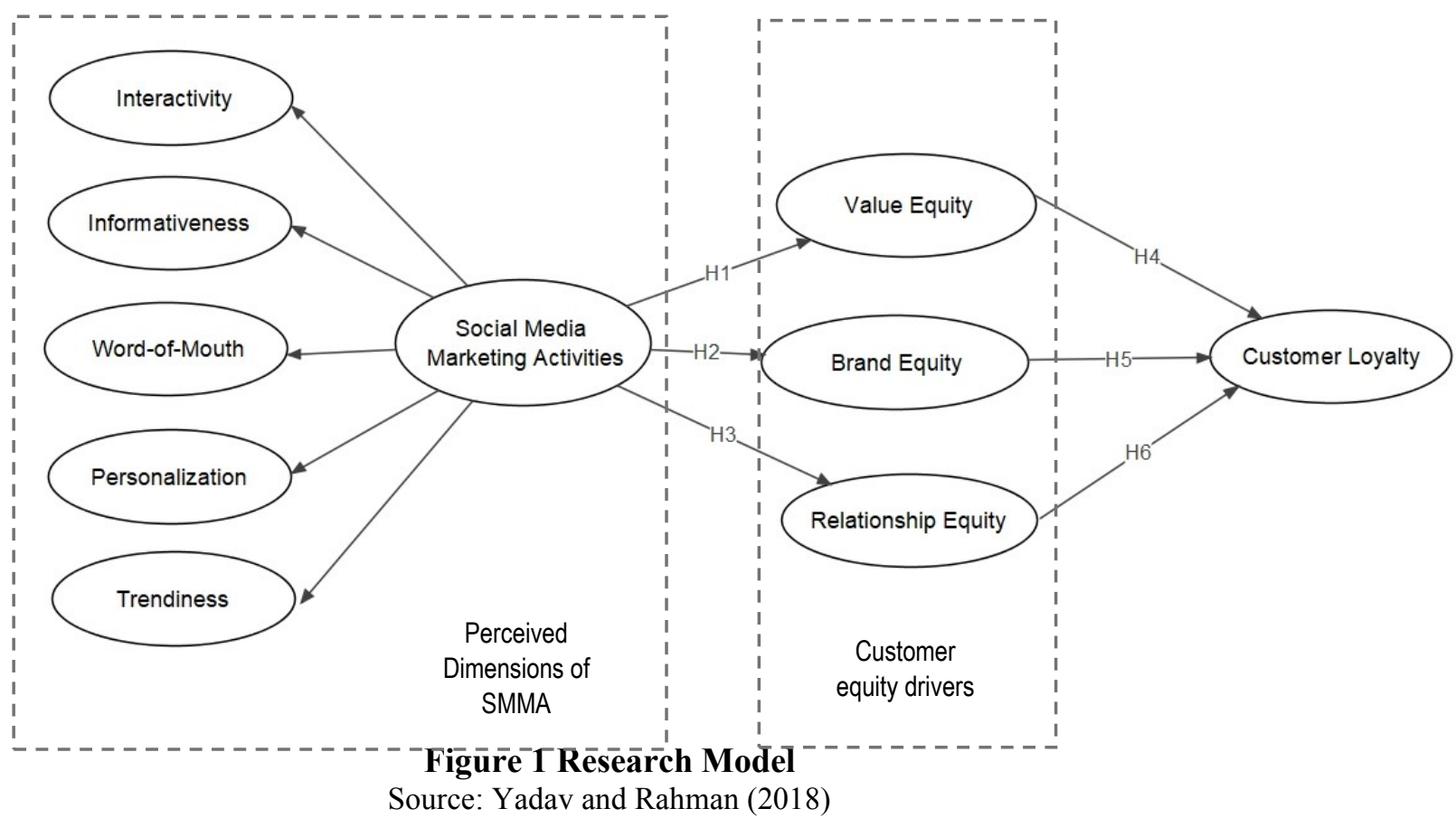

Drawing on earlier works from other researchers, Yadav \& Rahman (2018) suggest that prudent consumers tend to be value-conscious and concerned about quality and price. These consumers would tend to be more motivated to seek product information, process product information and arguments in marketing messages more systematically. Consequently, consumers would utilize social media sites and social commerce platforms as information sources to research products that can deliver the lowest available price for the desired level of quality and features (Yadav \& Rahman, 2018). Given the definition of value equity as an objective evaluation of the utility provided by a product based on what is given up for what is received (Ou et al., 2017), the more effective social media marketing activities engaged by an e-commerce firm, the more consumers able to assess the value utility of products they offer. 
The purpose of marketing activities is essentially establishing and maintaining communication with a large base of customers so that marketers can share product information and offerings to customers (Kim \& Ko, 2012). Through frequent and meaningful communication, marketers can enhance brand equity, which according to Keller (1993) is "the differential effect of brand knowledge on consumer response to the marketing of the brand". Keller (1993) propose that this brand knowledge stems from brand awareness and brand image (i.e. the perceptions about a brand as reflected by brand associations in consumers' memory. Social media marketing activities can contribute to building higher awareness and brand image through brand posts and engagements in social media. Bruhn, Schoenmueller, \& Schäfer (2012) suggest that communication stimuli (e.g. brand posts in social media and communication between consumers in social media) can trigger a positive effect in the consumer who received the communication stimuli. Consequently, Bruhn et al. (2012) suggest that the consumer's perception of the communication stimuli can result in a positive effect on the consumers' awareness and image of a brand.

Communication between a firm and its customers need to be maintained in the long term to build and increase relationship equity (Kotler \& Keller, 2016). Ou et al. (2017) propose that relationship quality reflect the customers' overall evaluation of their interaction quality with a company. Relationship quality reflects customers' tendency to remain in a relationship with a brand or firms beyond their objective and subjective assessments about the brand or firm (Kim \& Ko, 2012). Kim \& Ko (2012) suggest a brand's social media marketing activities through various social media platforms provide opportunities for customers to engage in communication with the brand and fellow users with a sincere and friendly manner so that the brand's communication efforts can result in increased relationship equity and brand equity.

Overall, the relationship between social media marketing activities and customer equity drivers was demonstrated in past research (e.g. Kim \& Ko, 2012; Yadav \& Rahman, 2018). Therefore, based on the aforementioned discussion and past research, the authors hypothesize:

H1: Perceived social media marketing activities has a direct positive influence on value equity

H2: Perceived social media marketing activities has a direct positive influence on brand equity

H3: Perceived social media marketing activities has a direct positive influence on relationship equity

The role of value equity, brand equity and relationship equity as loyalty drivers have been documented in past studies (Ou \& Verhoef, 2017; Ou et al., 2017; Rust et al., 2004). Drawing on past studies, Vogel, Evanschitzky, \& Ramaseshan (2008) explained the relationship between each element of customer equity drivers. Vogel et al. (2008) argue that since value equity can be regarded as the perceived ratio of what is received and what must be sacrificed, it can be explained using the equity theory perspective. Equity theory suggests that if someone's perceived outcome-input ratio corresponds to his/her reference outcome-input ratio, inner fairness is perceived. Consequently, it produces positive affective states that invoke positive attitudes such as satisfaction, loyalty and reduce switching propensity, which is a construct akin to loyalty (Vogel et al., 2008).

Brands with strong equity enjoy more favorable brand awareness and brand image, which is made of a set of brand associations formed through marketing communication efforts, such as building strong and unique selling proposition (Keller, 1993). Thus, a brand with strong equity can reduce perceived performance risk, and can lead to higher intentions to remain loyal to the brand. A brand with strong brand equity can also enjoy loyalty due to a more favorable perception of the brand that leads 
to an affective commitment toward it, which might consequently result in the improved likelihood of choosing that brand rather than competing brand (Vogel et al., 2008).

Brand equity and value equity may not be enough to maintain customers, and it requires relationship equity to tie customers to the firm (Lemon et al., 2001). Relationship equity refers to the customers' overall evaluation of their interaction quality with a company (Ou et al., 2017). If perceived relationship equity is high, consumers tend to feel a familiarity with the brand/store or personnel of the store/firm. In addition, they would tend to trust the product quality offered by the brand or store/firm and feel that the firm treat the customers well (Vogel et al., 2008). Vogel et al. (2008) suggest that based on confirmation-disconfirmation paradigm, consumers who believe that the interaction quality between them and the firm is better than what others experience would likely be satisfied with the offering, brand or the store, and therefore become more loyal. In a similar vein, Ou et al. (2017) maintain that based on reciprocity principle, customers who perceive a good relationship with a company tend to care about its welfare and avoid decisions that might harm the company (e.g. switch to competitors).

Based on the aforementioned discussion, the authors hypothesize:

H4: Value equity has a direct positive effect on customer loyalty.

H5: Brand equity has a direct positive effect on customer loyalty.

H6: Relationship equity has a direct positive effect on customer loyalty.

\section{Research Method}

\subsection{Sample And Data Collection}

The respondents in this study consist of social media users in greater Jakarta area who access social media daily, in possession of an account (as a shopper) in one of Indonesia's e-commerce firms, and at least had purchased from the e-commerce firm during the past three months before the survey was conducted. Sampling was conducted with convenience sampling as no sampling frame was available to the researchers. The data were collected using a self-administered questionnaire created using Google Forms, with the link to survey distributed through one of the authors' social media account and communication channels.

Before conducting the main survey, a pre-test was conducted on 40 respondents. Pre-test results indicated that all items met the minimum threshold of Cronbach's alpha (0.6) and factor loading of 0.7 as prescribed in (Hair Jr et al., 2014). Upon verification of preliminary item reliability, the authors proceeded with the main survey.

From the main survey, there were 242 total responses. Nevertheless, only 161 responses that met the screening criteria and subsequently used in data analysis. The sample size of 161 is deemed adequate since it has met the minimum sample size suggested by Anderson and Gerbing (1988 in Holbert \& Stephenson, 2002). These respondents consist of $54.7 \%$ female respondents and $45,3 \%$ male respondents, with $45 \%$ resided in Jakarta, and the remaining resided in the suburbs around Jakarta (Bogor, Depok, Tangerang and Bekasi). In terms of educational attainment, the majority of the respondents had attained an undergraduate or associate degree (68\%), and the rest $(32 \%)$ had attained a high school degree. This composition of educational attainment can be explained by the fact that $48 \%$ and $34 \%$ of the respondents had an occupation as employee and students, respectively.

\subsection{Measures}

All measures used in this study follows the measures used in Yadav \& Rahman (2018), translated to Bahasa Indonesia with some adaptations when required to suit the context. All translations were verified through back-translation into English to check for any possible mistranslation. Also, wording test was carried out before pre-testing 
to ensure questionnaire clarity and understandability. All indicators were measured with a seven-point Likert scale.

\section{Result}

To analyze the data, the authors used Lisrel 8.51 for structural equation modelling, which consists of two stages: confirmatory factor analysis or measurement model analysis and structural model analysis. For the confirmatory factor analysis stage, most of the goodness of fit test for the measurement model indicated a marginal fit with the data $\left(x^{2} / d f=2.090, \mathrm{GFI}=0.76, \mathrm{AGFI}=0.71, \mathrm{NFI}=0.75, \mathrm{CFI}=0.85\right)$, but the root mean square error of approximation $(\mathrm{RMSEA}=0.076)$ shows a good fit (cf. Hair Jr et al., 2014).

Table 1 indicates the confirmatory factor analysis and reliability of each construct. Construct reliability was ascertained based on composite reliability (CR), and convergent validity was ascertained based on average variance extracted (AVE) and factor loadings of the indicators. From Table 1, it can be seen that all first-order constructs demonstrated value between 0.75 and 0.98 , which is above the recommended threshold of 0.7 (Nunnally \& Bernstein, 1994). Meanwhile, in terms of convergent validity, almost all indicators construct exhibited factor loadings above 0.5 with significant $\mathrm{T}$-value (above 1.96). Social media marketing activities construct was modelled as a second-order construct that consists of five dimensions (i.e. interactivity, informativeness, word of mouth, personalization and trendiness). From Table 1, have $\mathrm{CR}$ and $\mathrm{AVE}$ ( 0.81 and 0.60 , respectively) fulfilled the minimum value of CR and AVE prescribed by Nunnally \& Bernstein (1994). In terms of factor loadings, all factor loadings of the second-order factor were significant ( $\mathrm{T}$ value $>1.96)$.

Table 1 Confirmatory Factor Analysis and Reliability

\begin{tabular}{|c|c|c|c|c|c|}
\hline Construct & Indicator & $\begin{array}{c}\text { Standardized } \\
\text { Factor Loadings }\end{array}$ & T-value. & $\mathrm{CR}$ & AVE \\
\hline \multirow[t]{3}{*}{ Interactivity } & INT1 & 0.80 & 10.85 & 0.80 & 0.58 \\
\hline & INT2 & 0.79 & 10.71 & & \\
\hline & INT3 & 0.68 & 8.89 & & \\
\hline \multirow[t]{3}{*}{ Informativeness } & INF1 & 0.68 & 9.20 & 0.80 & 0.57 \\
\hline & INF2 & 0.81 & 11.47 & & \\
\hline & INF3 & 0.76 & 10.47 & & \\
\hline \multirow[t]{3}{*}{ Word of mouth } & WOM1 & 0.81 & 11.48 & 0.87 & 0.68 \\
\hline & WOM2 & 0.85 & 12.26 & & \\
\hline & WOM3 & 0.72 & 9.83 & & \\
\hline \multirow[t]{3}{*}{ Personalization } & PERS1 & 0.74 & 10.08 & 0.80 & 0.57 \\
\hline & PERS2 & 0.80 & 11.11 & & \\
\hline & PERS3 & 0.73 & 9.88 & & \\
\hline \multirow[t]{3}{*}{ Trendiness } & TREND1 & 0.54 & 6.92 & 0.80 & 0.58 \\
\hline & TREND2 & 0.83 & 11.96 & & \\
\hline & TREND3 & 0.87 & 12.66 & & \\
\hline \multirow[t]{5}{*}{ SMMA } & Interactivity & 0.44 & 4.66 & 0.81 & 0.60 \\
\hline & Informativeness & 0.79 & 7.44 & & \\
\hline & Word of mouth & 0.59 & 6.43 & & \\
\hline & Personalization & 0.71 & 7.19 & & \\
\hline & Trendiness & 0.63 & 5.46 & & \\
\hline \multirow[t]{3}{*}{ Value equity } & VE1 & 0.66 & 8.96 & 0.82 & 0.61 \\
\hline & VE2 & 0.83 & 12.18 & & \\
\hline & VE3 & 0.84 & 12.38 & & \\
\hline \multirow[t]{2}{*}{ Brand equity } & BE1 & 0.80 & 11.78 & 0.98 & 0.61 \\
\hline & BE2 & 0.83 & 12.59 & & \\
\hline
\end{tabular}




\begin{tabular}{llcccc} 
& BE3 & 0.83 & 12.64 & & \\
& BE4 & 0.74 & 10.62 & & \\
Relationship & BE5 & 0.78 & 11.53 & & \\
equity & RE1 & 0.63 & 8.47 & 0.75 & 0.50 \\
& RE2 & 0.70 & 9.79 & & \\
Customer & RE3 & 0.79 & 11.35 & & \\
loyalty & CLI1 & 0.70 & 9.70 & 0.97 & 0.53 \\
& CL2 & 0.71 & 9.95 & & \\
& CL3 & 0.82 & 12.19 & & \\
& CL4 & 0.74 & 10.44 & & \\
& CL5 & 0.73 & 10.33 & & \\
\hline
\end{tabular}

The path diagram from the structural model analysis is presented in Figure 2. Before examining the significance and beta coefficients of the paths, the goodness of fit needs to be examined. In terms of overall fit indices, the model exhibited $x^{2} / d f=$ $2.23, \mathrm{GFI}=0.73, \mathrm{AGFI}=0.68, \mathrm{NFI}=0.71, \mathrm{CFI}=0.82$ and $\mathrm{RMSEA}=0.076$. These fit indices are fairly similar to the results from the CFA stage, which mostly suggest marginal fit and only RMSEA that suggest good fit. However, Hair Jr et al. (2014) suggest that besides aiming to achieve a good fit, a model should also ensure other measures of validity. Despite having a marginal fit, this research model has fulfilled validity and reliability criteria that warrant some merit on this structural model.

From figure 2 and table 2, the structural model indicated that all paths from social media marketing activities (SMMA) to the three customer equity drivers (H1-H3) were found significant at $\mathrm{p}<0.01$. Table 2 indicates that perceived SMMA has a positive relationship with value equity $(\beta=0.75, \mathrm{t}=7.07, \mathrm{p}<0.0001)$, brand equity $(\beta=0.70$, $\mathrm{t}=7.90, \mathrm{p}<0.0001)$, and relationship equity $(\beta=0.90, \mathrm{t}=8.65, \mathrm{p}<0.0001)$. Among the three customer equity drivers (H4-H6), only value equity that was not found to have a significant positif relationship with customer loyalty $(\beta=0.18, t=1.62, p>0.05)$. In contrast, brand equity has a positive relationship with customer loyalty $(\beta=0.30, \mathrm{t}=$ $3.06, \mathrm{p}<0.01)$, and relationship equity also has a positive relationship with customer loyalty $(\beta=0.41, \mathrm{t}=3.06, \mathrm{p}<0.01)$.

The mediating effect of the three customer equity drivers was also examined. Table 3 shows the indirect effects of social media marketing activities on customer loyalty through the three customer equity drivers. Besides calculating the indirect effect size, the authors also include a Sobel test calculated with an online Sobel test calculator (Preacher \& Leonardelli, 2020). The indirect effect analysis suggests that the strongest indirect effect demonstrated by SMMA $\rightarrow$ Relationship Equity $\rightarrow$ Customer loyalty path $(\beta=0.369, p<0.005)$. The SMMA $\rightarrow$ Brand equity $\rightarrow$ Customer loyalty path $(\beta$ $=0.21, \mathrm{p}<0.005)$ had the second-highest indirect effect. On the other hand, the SMMA $\rightarrow$ Value equity $\rightarrow$ Customer loyalty path was the weakest of the three and not found significant $(\beta=0.135, \mathrm{p}<0.005)$ since the path between Value equity and Customer loyalty was not significant $(\beta=0.18, \mathrm{t}=1.62, \mathrm{p}>0.05)$.

Table 2 Hypothesis Testing Results

\begin{tabular}{lrll}
\hline \multicolumn{1}{c}{ Hypothesis } & $\beta$ & T-value & Test results \\
\hline H1: SMMA $\rightarrow$ Value equity & 0.75 & 7.07 & Supported \\
H2: SMMA $\rightarrow$ Brand equity & 0.70 & 7.90 & Supported \\
H3: SMMA $\rightarrow$ Relationship & 0.90 & 8.65 & Supported \\
equity & & & Not Supported \\
$\begin{array}{l}\text { H4: Value equity } \rightarrow \text { Customer } \\
\text { Loyalty }\end{array}$ & 0.18 & 1.62 & \\
$\begin{array}{l}\text { H5: Brand equity } \rightarrow \text { Customer } \\
\text { Loyalty }\end{array}$ & 0.30 & 3.06 & Supported \\
$\begin{array}{l}\text { H6: Relationship } \\
\rightarrow \text { Customer Loyalty }\end{array}$ & & & \\
\hline
\end{tabular}




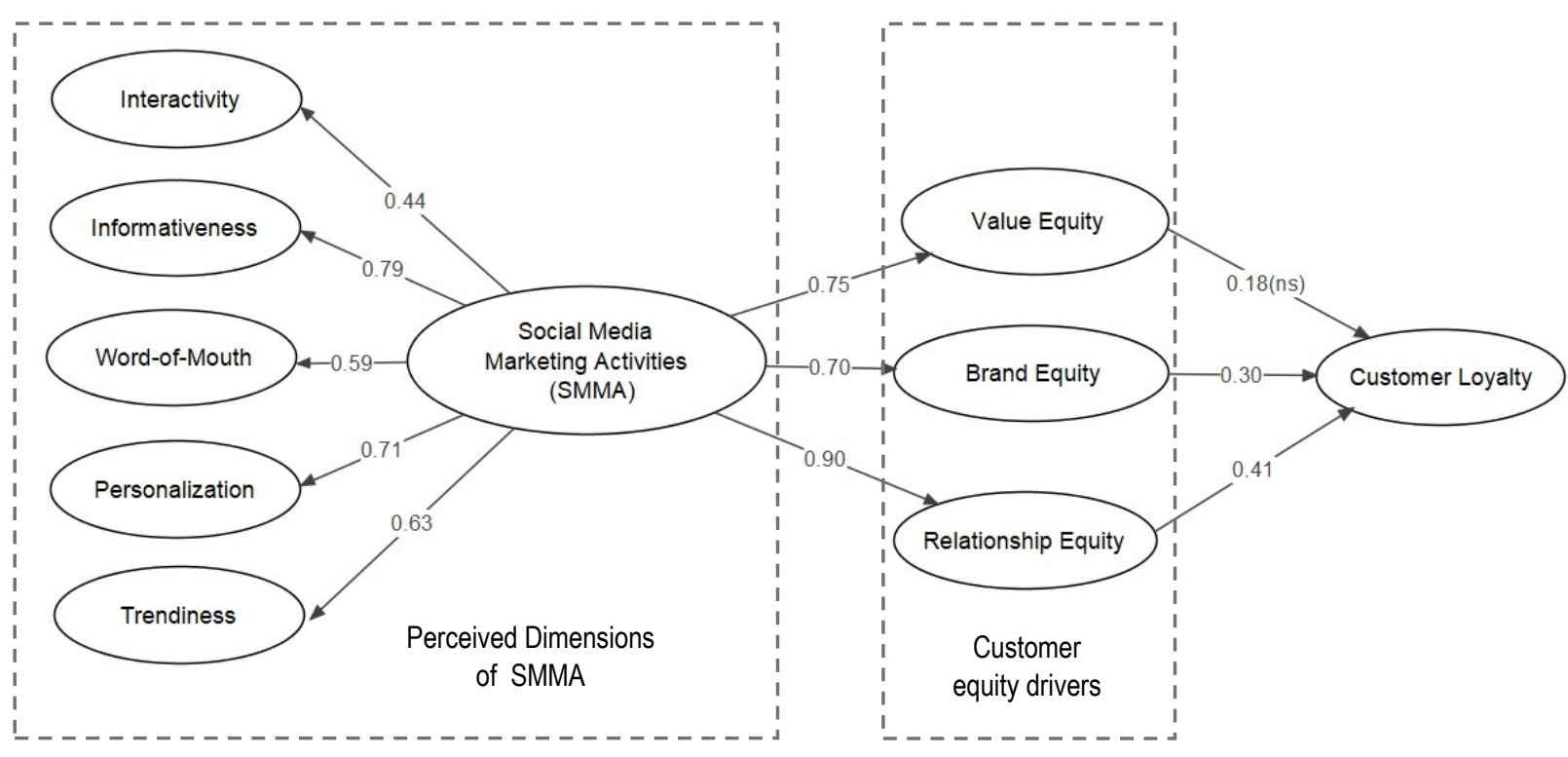

Figure 1 Structural Model

Table 3 Indirect Effects

\begin{tabular}{llcc}
\hline \multicolumn{1}{c}{ Path } & & $\begin{array}{c}\text { Indirect } \\
\text { effects }\end{array}$ & $\begin{array}{c}\text { Sobel test } \\
\text { p-value }\end{array}$ \\
\hline $\begin{array}{l}\text { SMMA } \rightarrow \text { Value equity } \rightarrow \text { Customer } \\
\text { loyalty }\end{array}$ & 0.135 & $0.108(\mathrm{~ns})$ \\
$\begin{array}{l}\text { SMMA } \rightarrow \text { Brand equity } \rightarrow \text { Customer } \\
\text { loyalty }\end{array}$ & 0.21 & 0.004 \\
$\begin{array}{l}\text { SMMA } \rightarrow \text { Relationship Equity } \rightarrow \\
\text { Customer loyalty }\end{array}$ & 0.369 & 0.003 \\
\hline
\end{tabular}

\section{Discussion}

Most of the findings from this study confirm the findings of Yadav \& Rahman (2018). Yadav and Rahman (2018) found that social media marketing activities affect all customer equity drivers, and all three customer equity drivers affect customer loyalty. This study found a similar result, with one exception: the path between value equity and customer loyalty was not found significant. Notwithstanding, the notion from past studies (e.g. Kim \& Ko, 2012) that social media marketing activities conducted by e-commerce firm can affect customer equity drivers seem to be validated in this study. A well-targeted and well-crafted social media marketing messages aimed at e-commerce customers can engage the customers and "glue" the customers into a relationship with the e-commerce firms. Kim and Ko (2012) also suggest that social media marketing messages build value equity by providing novel value to customers. They suggest that this novel value may come from the e-commerce's use of social media platforms to reach and communicate with their customers, which allow customers to engage in sincere and friendly communication with the firm and other users, thereby building relationship equity and brand equity along with value equity (Kim \& Ko, 2012). This suggestion is corroborated with the confirmatory factor analysis result that indicates the significance of the interactivity dimension of social media marketing activities, indicating that the customers perceived that social media marketing activities engaged by e-commerce firms in Indonesia reflect interactivity dimension. 
Besides interactivity, Results from this study indicate that informativeness, personalization and trendiness were the three most important dimensions of social media marketing activities. Lee \& Hong (2016) also suggest that informativeness, a dimension of social media marketing activity, can also shape value and fulfil customers' utilitarian need by providing quality information that can help consumers make optimal purchases. In addition, they also added that the need to consume something new, original and novel is a fundamental human need (i.e. something trendy). Thus, it is logical that if an e-commerce firm can deliver informative and trendy messages in its social media posts, it can build its relationship equity, value equity and value equity.

In this study, social media marketing activities had the highest effect on relationship equity, followed by value equity and brand equity. This finding suggests that from this study, e-commerce users who follow the e-commerce firms' social media accounts seem to perceive that the e-commerce firms' social media promotes relationship equity. Relationship equity can be built through various ways, such as loyalty programs, customer communities, and knowledge-building programs (Lemon et al., 2001; Ou et al., 2014) as well as by building engagement with customers. Zollo, Filieri, Rialti, \& Yoon (2020) suggest that past research has indicated that social media marketing activities often involve raffles, design contests, and customization opportunities that enhance brand-to-customer interaction and customer-to-customer interaction, which in turn make customers feel like part of a community. This sense of community is an important source of relationship equity (Ou et al., 2014). A casual observation of Indonesia's top e-commerce firms' social media pages suggests that their brand posts did consist of raffles, contests and informational posts such as product-related and sales promotion related information. Besides, the tone they used reflects the current trend that seems to be aimed at millennials, hence enhancing resonance with the target market.

This study only managed to find support for the relationship between brand equity and customer loyalty and the relationship between relationship equity and customer loyalty, with relationship equity demonstrated higher effect on customer loyalty. Analysis of indirect effect also suggests that the indirect effect of social media marketing activities was stronger through relationship equity. This finding reflects the explanation from Vogel et al. (2008) discussed in the literature review section that perceived relationship equity can induce customers to fell a familiarity with the ecommerce firm, and subsequently build trust and satisfaction with the product quality and services provided by the e-commerce firm, and eventually becomes more loyal.

The role of social media marketing activities in building brand equity, which subsequently affects loyalty, was also validated in this study. Given the concept of brand equity as a positive differential effect brought by brand awareness and set of favorable associations (brand image) proposed by (Keller, 1993), it can be construed that social media marketing activities can be used by e-commerce firms as a means to build awareness and positive brand associations that increase preference and affective commitment toward the brand (Vogel et al., 2008).

The path between value equity and customer loyalty was not significant at a 95 per cent confidence level. In this study, value equity was operationalized as the perceived ratio of what is received and what must be sacrificed, which among others, include the level of effort and price-quality ratio as it measures. This finding may be explained with the three-factor theory of satisfaction (Matzler \& Sauerwein, 2002). The three-factor theory of satisfaction suggests three satisfaction factors that consist of basic factors, excitement factors, and performance factors. The basic factors are called dissatisfiers. These factors serve as minimum requirements which must be provided, otherwise might lead to customer dissatisfaction. But its mere existence is not sufficient to create satisfaction. Meanwhile, excitement factors (satisfiers) are unexpected factors that are not expected, and it tends to increase customer satisfaction if provided, but do not lead to dissatisfaction if not provided. The third factor, which is called the 
performance factors, could stimulate satisfaction if its performance is high, and it could lead to dissatisfaction if its performance is low (Matzler \& Sauerwein, 2002). The ecommerce competitive landscape in Indonesia has been relatively intense. Prominent e-commerce firms in Indonesia strive to outperform each other by providing various features, ease of use and competitive prices (including sales promotions) aimed at providing the best value equity for their customers. One can look up the same product on different e-commerce firms application or website. The search results normally yield in products that are comparable in price and sales promotions available for customers (e.g. free delivery fees, cashback, etc.), even sometimes the products were offered by the same seller in two or more marketplaces (in case of $\mathrm{C}$ to $\mathrm{C}$ ecommerce/marketplace). This condition might cause the customers to view value equity not as a motivating factor, but maybe as a basic factor that must be provided, but not necessarily make the customers loyal to the e-commerce firm. Note that despite the three-factor theory specifically related to satisfaction, but the marketing literature is rife with evidence of a strong link between satisfaction and loyalty (Choi, Seol, Lee, Cho, \& Park, 2008; Faraoni, Rialti, Zollo, \& Pellicelli, 2019; Tzavlopoulos, Gotzamani, Andronikidis, \& Vassiliadis, 2019).

\section{Conclusion}

This study examined the role of social media marketing activities in affecting customer loyalty through customer equity drivers as mediating variables. This study offers several findings. Firstly, the social media marketing activities dimensions (interactivity, informativeness, word-of-mouth, personalization, and trendiness) proposed in (Yadav \& Rahman, 2018) was supported. Secondly, this study also corroborates Yadav \& Rahman's (2018) finding that social media marketing activities affect customer equity drivers (value equity, brand equity, and relationship equity). Thirdly, in contrast to Yadav \& Rahman (2018), this study only found support for the relationship between two out of three elements customer equity drivers and customer loyalty (i.e. brand equity and relationship equity), while the relationship between value equity and customer loyalty was not found significant.

Theoretical implications of this study are twofold. Firstly, since the proposed dimensions of social media marketing activities proposed by (Yadav \& Rahman, 2018) was evident from this study, future research could try to investigate further how ecommerce firms (particularly in Indonesia) apply each dimension in their social media marketing activities. By documenting how the e-commerce firms conduct their social media marketing activities (i.e. examine the form of message/activities, the appeal, tone, and execution-style used in brand posts), researchers in social media field can get some insights as to the how the effective elements marketing message that resonates with each was crafted, and how effective those social media messages are in delivering the desired outcome. This type of research can contribute further understanding of persuasive message characteristics e-commerce and social media context.

Secondly, this study did not find enough evidence of the relationship between value equity and customer loyalty. The fact that the T-value on the Value equity $\rightarrow$ customer loyalty path $(\beta=0.18, \mathrm{t}=1.62, \mathrm{p}>0.05)$. was only slightly below the critical value of $\mathrm{T}$-value $=1.65$ suggest that perhaps this condition was caused by the small number of respondents (161) in this study. Further research can attempt to validate this result using a larger sample size.

The five social media marketing dimensions proposed in Yadav and Rahman (2018) were found to be valid dimensions of social media marketing activities. In addition, from the study, social media marketing activities seem to affect customer loyalty through the relationship equity pathway more than through brand equity and value equity pathways. This finding emphasizes the need for marketers to use social media marketing activities to build relationship equity as a means to foster customer loyalty. For managers of e-commerce firms, there are several managerial implications 
derived from these findings that might be relevant. First, e-commerce firms need to pay attention along the informativeness dimension, as it was shown to be the most important social media marketing activity dimensions. Not only marketers need to ensure continual updating of social media contents, but they also need to make sure the brand posts provide information that resonates with the needs and desire of customers. Informativeness also needs to be coupled with trendiness, whereby e-commerce firms need to ensure that the execution-style (e.g. appeal, tone and message strategy) of their social media posts need to reflect the style, issues or language, etc. that is currently "happening" or trending.

Secondly, e-commerce firms need to ensure a lively interaction between the firm and its customers who subscribe to its social media pages or channels. Prompt responses to comments and direct messages are key activities that can help build interactivity, which not only helps to create and nurture a relationship between the firm and its customers, but it eventually might help to foster loyalty. A high factor loading on personalization dimension also implied that e-commerce firms need to try to deliver personalization of its social media marketing activities. At a very minimum, every response to comments or direct messages should address the customer by name, and avoid using standardized response template. Whereby possible, each response to comments or direct messages needs to be perceived as if it was written personally by human administrators for each customer who made the comments/direct messages, even if, in reality, it was crafted by an artificial intelligence/bots. A perceived human touch with remarks tailored for each query would arguably improve the social media marketing activity along the personalization dimension.

Third, the e-commerce firms must strive to create brand posts that are worthy for E-WOM. Perhaps giveaways or sales promotion programs that require users to tag other users or share contents to other users can be considered as a means to increase EWOM. Alternatively, e-commerce firms can regularly create special promotions (but at a random interval or schedule) that are available only for customers who follow the firm's social media channels and allow the customers to share information about such special promotions to other customers. These programs might help to address the importance of perceived word of mouth dimension.

In terms of limitations, this study faced some limitations. First, the authors only managed to gather a usable sample size of 161 respondents due to time constraints and limited data collection resources. Also, the demographic makeup in this sample was limited to customers who lived in the greater Jakarta area. Future research can expand the geographic coverage to include other major cities in Indonesia, or perhaps smaller cities or regencies in Indonesia, and see if there is any different result in terms of the factor structure of social media marketing activities as well as the structural relationships between the cities. The second limitation is in terms of the variables studied. This study was only focused on variables proposed by Yadav and Rahman (2018), and did not modify or added new variables. Zollo et al. (2020) found that the relationship between social media marketing activities perceived by customers and brand equity was mediated by benefits (cognitive, personal integrative, and social integrative benefits). Perhaps, future research can incorporate benefits proposed by Zollo et al. (2020) as a mediating variable in the model. Besides adding an intervening variable, perhaps future research can also investigate the motivation that drives ecommerce customers to follow e-commerce firms' social media.

\section{References}

Bojanic, D., \&Warnick, R. (2012). The Role Of Purchase Decision Involvement In A Special Event. Journal of Travel Research, 51 (3), 357-366. https://doi.org/10.1177/0047287511418364 
Cha, M., Yi, Y., \& Bagozzi, R. (2015). Effects Of Customer Participation In Corporate Social Responsibility Programs On The CSR-Brand Fit And Brand Loyalty. Cornell Hospitality Quarterly, 57(3), 1-15. https://doi.org/10.1177/1938965515620679

Choi, Y., Ok, J., \& Hyun, S. (2017). Relationships between brand experiences, personality traits, prestige, relationship quality, and loyalty: an empirical analysis of coffeehouse brands. International Journal of Contemporary Hospitality Management, 29(4), 1185-1202.

Huang, C. Y., Chou, C. J., \& Lin, P. C. (2010). Involvement Theory In Constructing Bloggers' Intention To Purchase Travel Products. Tourism Management, 31, 513-526. 10.1016/j.tourman.2009.06.003.

Kim, D., \& Jang, S. (2014). Motivational drivers for status consumption: A study of Generation Y consumers. International Journal of Hospitality Management. 38. 39-47. 10.1016/j.ijhm.2013.12.003.

Kim, S. H., \& Lee, S (Ally). (2017). Promoting Customers' Involvement With Service Brands: Evidence From Coffee Shop Customers. Journal of Service Marketing, 31(7), 12.

Kinard, B. R., \& Capella, M. (2010). Relationship Marketing: The Influence Of Consumer Involvement On Perceived Service Benefits. Journal of Services Marketing. 31(4), 513-526. 10.1108/08876040610691257

Laaksonen, P. (1994). Consumer Involvement: Concepts and Research. Routledge.

Ladik, D., Carrillat, F., \& Tadajewski, M. (2015). Belk's (1988) "Possessions and the extended self" revisited. Journal of Historical Research in Marketing, 7, 184207. 10.1108/JHRM-06-2014-0018.

Lee, S., Kim, K., \& Sundar, S. (2015). Customization In Location-Based Advertising: Effects Of Tailoring Source, Locational Congruity, And Product Involvement On Ad Attitudes. Computers in Human Behavior, 51, 336-343.

Li, X., \& Petrick, J. (2008). Examining the Antecedents of Brand Loyalty from an Investment Model Perspective. Journal of Travel Research. J TRAVEL RES. 47. 25-34. 10.1177/0047287507312409.

Mittal, B., \& Lee, M. S. (1989). A Causal Model Of Consumer Involvement. Journal of Economic Psychology, 10(3), 363-389. https://doi.org/10.1016/0167$\underline{4870(89) 90030-5}$

Mowen, J. C. (1995). Consumer Behavior. Pearson.

Olsen, S. (2007). Repurchase Loyalty: The Role Of Involvement And Satisfaction. Psychology and Marketing, 24, 315 - 341. 10.1002/mar.20163.

San Martín, S., San José, R., \& Camarero, C. Does Involvement Matter in Online Shopping Satisfaction and Trust? (2011). Psychology and Marketing. 28(2). $\underline{10.1002 / m a r .20384}$

Sierra, J., \& Mcquitty, S. (2005). Service Providers And Customers: Social Exchange Theory And Service Loyalty. Journal of Services Marketing, 19. 392-400. $10.1108 / 08876040510620166$. 
The Role of Social Media Marketing Activities on Customer Equity Drivers and Customer Loyalty

Zeithaml, V. (1988). Consumer Perceptions of Price, Quality and Value: A Means-End Model and Synthesis of Evidence. Journal of Marketing, 52. 2-22. $10.1177 / 002224298805200302$. 